\section{Feeding practices for toddlers with stunting in Jakarta: A case study}

\author{
Sri Melfa Damanik ${ }^{1,2}$, Dessie Wanda1, \\ Happy Hayati ${ }^{1}$ \\ 1 Faculty of Nursing, Universitas \\ Indonesia; ${ }^{2}$ Nursing Department, \\ Universitas Kristen Indonesia
}

\begin{abstract}
Stunting represents a child's failure to thrive. On the basis of the World Health Organization child growth standards, stunting is a height of $<-2 \mathrm{SD}$ of the $\mathrm{z}$-score for the child's age. There are several major causes of stunting. One is the inability to optimize child feeding practices. The aim of this study was to explore the feeding practices that lead to stunting in toddlers in Jakarta. The participants in this study were 15 mothers. Content analysis was the method that was chosen for this study. The data analysis revealed four themes that describe the feeding practices for toddlers with stunting in Jakarta: i) mothers providing instant porridge and ready-to-serve steamed chicken rice; ii) a feeding frequency of small portions only 23 times per day; iii) a lack of diet diversity; and iv) the suboptimal intake of iron-rich foods. The provision of effective education about appropriate feeding practices to pregnant women and mothers with toddlers is expected to reduce the incidence of stunting in Indonesia.
\end{abstract}

\section{Introduction}

The achievement of optimal child growth and development is essential for enhancing a country's position on the human development index. This must be supported by a good nutritional status: the main requirement during a child's growth period. Appropriate feeding practices accompanied by strict supervision are an indicator that needs to be considered for overcoming the problems related to child growth disorders, one of which is stunting. ${ }^{1-3}$

Stunting is currently one of the world's biggest problems. The WHO has predicted that 127 million toddlers will experience stunting by 2025 . The WHO's global target for 2025 is to reduce stunting in this age group by $40 \%$. Globally, $22.9 \%$ of toddlers suffered from stunting in 2016. It is defined as the height-to-age ratio $<-2 S D$ based on the WHO $z$-scores provided in the WHO growth standards. 4

Studies have shown the effects of stunt- ing on child growth and development. A study showed that physical growth disorders in which there is a high ratio between normal children and stunting children where children with stunting have more physical growth disorder than normal children, cognitive impairments, and the increased risk for chronic diseases, such as obesity. ${ }^{5}$ Children with nutritional problems earn poor grades because of difficulties with concentration, goal-setting, and memory. ${ }^{6}$ In addition, there can be motor function disorders, such as lethargy and difficulties with crawling, walking, and interacting with the environment.?

The practice of providing good food is an indicator for assessing the optimization of children's nutritional needs. In many countries, the optimization of toddlers' diets through the provision of complementary foods is still widespread. Complementary foods are often introduced before or after the age of 6 months in situations of suboptimal nutrition. 8,9 The age of 2 is a very critical period for growth and development, which can be achieved through optimal feeding. ${ }^{10}$ In South Ethiopia, poor feeding can result in malnourishment in one-third of children, and it can become a strong predictive factor for stunting. ${ }^{3}$

Feeding practices that fail to meet the standard can increase the risk of stunting in toddlers. A study of 6-23-month-old children found that those who did not have varied diets were more likely to experience stunting than those who consumed diverse foods, i.e., a diet representing $\geq 5$ food groups. ${ }^{11}$ Other studies have found a significant relationship between diet diversity and the $z$-score indicators for body length for age $(\mathrm{PB} / \mathrm{U})$ and height for age, according to the $\mathrm{Z}$-score. ${ }^{12,13}$ Therefore, diet diversity is important in the discussions of solutions for maintaining the optimal nutritional needs of children and preventing stunting.

In addition to ensuring dietary diversity, optimal feeding practices must include the provision of iron-rich foods with the frequency that considers the child's age. Infants who do not experience the minimum dietary diversity and feeding frequency are significantly more likely to have stunted growth. ${ }^{10}$ Dietary diversity starts at pregnancy. The children of mothers who do not increase their food consumption during pregnancy and breastfeeding have a higher chance of experiencing stunting than those of mothers whose consumption is adequate during these periods. ${ }^{3}$ Inadequate nutrition will certainly inhibit child growth and development; therefore, the achievement of ideal nutritional standards is critical.

Poor child feeding practices have been observed in several developing countries,
Correspondence: Dessie Wanda, Pediatric Nursing Department, Faculty of Nursing, Universitas Indonesia, Jalan Prof. Dr. Bahder Djohan, Kampus UI Depok, West Java, 16424 Indonesia.

Tel.: +6221.78849120 - Fax: +6221.7864124.

E-mail: dessie@ui.ac.id

Key words: Toddlers; feeding practices; stunting.

Acknowledgments: The writer would like to express his gratitude to all mothers who participated in this study.

Funding: This study was supported by Hibah PITTA B 2019 DRPM UI No. NKB0488/UN2.R3.1/HKP.05.00/2019 for funding this research.

Contributions: SMD substantial contributions to the conception of the work; acquisition, analysis, or interpretation of data for the work. DW and $\mathrm{HH}$ supervised the findings of this work; final approval of the version to be published. All authors discussed the results and contributed to the final manuscript.

Ethical approval: Approval was received from the Research Ethics Committee of the Faculty of Nursing Universitas Indonesia before the study began No.43/UN2.F12.D/HKP.02.04/2019.

Conflict of interest: There is no conflict of interest in this study.

This work is licensed under a Creative Commons Attribution NonCommercial 4.0 License (CC BY-NC 4.0).

CCopyright: the Author(s), 2020

Licensee PAGEPress, Italy

Pediatric Reports 2020; 12(s1):8695

doi:10.4081/pr.2020.8695

including Indonesia. Therefore, researchers are interested in examining the feeding practices for stunted children. The goal of this qualitative study was to explore the feeding practices for toddlers who were experiencing stunting in Jakarta.

\section{Materials and Methods}

A qualitative case study approach to explore and describe the feeding practices for children with stunted growth.

The participants were selected on the basis of the inclusion criteria determined by the researchers: mothers with 12-36-monthold toddlers with stunted growth. Stunting was measured by the ratio of height or body length to age $<-2$ SD based on the WHO $z$ score tables for child growth standards. Another criterion was that the mothers fed 
their children every day. There were 15 participants, and data saturation was achieved with the interview of the $15^{\text {th }}$ participant. The participants were selected through purposive sampling. The research was conducted in two district health centers in Jakarta from September 2018 to April 2019.

In-depth interviews were conducted to obtain information about the feeding practices for toddlers experiencing stunting in Jakarta. The interviews, which were conducted at the participants' homes, lasted 30-50 minutes. The researchers used an interview guide that contained seven open questions related to the indicators of the feeding practices recommended by the WHO. The researcher's tape-recorded the participants' responses and took field notes to document their observations during the interviews. The interviews were transcribed verbatim. For ensure accuracy, the participants' confirmation of their statements was sought before the completion of the interviews and after data analysis. Content analysis, which allows for the analysis of the participants' answers to each question, was performed.

Data validity was achieved through the following steps: i) the researcher extended the interview when necessary to provide clarification and to obtain confirmation; ii) a detailed description of the interview was written; and iii) a structured analysis was performed. The analysis began with the verbatim transcriptions of the interviews. Next, the themes and sub-themes were identified. Transition theory provided the framework for the study. During the discussion and identification of the themes, the researcher consulted the expert researcher; iv) for maintaining the validity of the research, researcher using participant taking techniques by maximizing participant variation, consultation with expert researchers, and confirmation with participants again.

For ensuring the validity of the study, the following procedures were performed: i) a research plan proposal was sent to the FoN Ethics Committee; ii) trust was established with the participants by extending the length of the interviews and clearly explaining the research procedures; iii) the researcher immediately confirmed the participants' statements at the end of the interviews. After the identification of the themes, the data were again confirmed with the participants. This time it was done through social media, namely the WhatsApp application; iv) the researchers performed a structured data analysis, which began with the verbatim transcription. Next was data categorization, which included the identification of the themes and subthemes; v) the researchers conducted regu- lar meetings with expert researchers to check the interview transcripts and the data analysis process.

\section{Results \\ Participant characteristics}

The 15 participants were mothers of toddlers with stunting. Eight lived in the vicinity of the Kramatjati District Public Health Center in East Jakarta. The remaining seven were residents of the area surrounding the Cipayung District Health Center in East Jakarta. The participants were aged 17-44. Their education levels were as follows: 2 had completed elementary school; 6 , junior high school; 6 , high school; and 1, a bachelor's degree. All of the participants had the same occupation. They were housewives. The children were 13-32 months old: 8 girls and 7 boys. On the basis of the length or height, as measured by the WHO $z$-score tables for child growth standards, 4 children were categorized as short, and 11 as very short.

\section{Themes}

\section{Theme 1: Complementary feeding with instant porridge and fast food steamed rice}

Mother stated that at 6 months old, her infant was given bananas and instant porridge:

At 6 months ... exactly ... 6 months ... the banana is scraped like that ... and mixed ... with tap water ... First, the tap water ... and then the banana and Nestlé milk ... brewed... Then at 7 months ... provided with steamed rice ... At 7 months, I provided him with steamed rice... Then at 8 months ... I introduced him to mushy rice. (Lucy)

A mother revealed that she bought porridge because she was busy with the child:

Sometimes I bought it. Sometimes I cooked it ... I bought it when I didn't have enough time ... But I cooked it when I had the time ... I mostly bought it, however ... I don't have time to cook because I have three children ... Yes. Preoccupied with my children. (Emily)

A participant stated that she bought the porridge due to close to school time:

Sometimes I made it ... I made it on my own by blending it... Otherwise, I bought it ... especially when it was close to school time ... (chuckle). (Juliet)

A participant stated that she bought instant porridge because of laziness:

Sometimes when I'm lazy to cook ... I buy milk porridge ... Nestlé ... when I'm busy with this ... or don 't have time ... or I'm in a hurry. (Emily)

\section{Theme 2: Feeding frequency-smaller portions 2-3 times per day}

Some mother stated that her child ate half of a ladle of rice 3 times per day:

When the mealtime comes, I feed him breakfast, lunch, and dinner with half of a rice ladle [half of a baby plate]: 4 to 5 spoons. (Alice)

Another mother stated that her child ate less than half of a portion 3 times per day:

He eats three times a day ... Oops! ... Not even half of the plate ... Just a little ... He just doesn't eat that much ... only a little, but at least he has enough intake ... Better than feeling satiated and then vomiting. (Annabel)

A mother stated that her child ate less than half a bowl 2 times per day:

Two times a day at the maximum ... breakfast ... snack at noon ... and, later, dinner ... He eats a small bowl ... or even half of it ... .Yeah, that's his portion. (Milly)

A mother stated that her child ate half of a bowl 3 times per day:

He eats 3 or 4 times ... mostly 3 times ... He can eat up to 2 bowls ... maybe 6 spoons ... When he was under 2 years old ... it was so difficult to feed him, but after 2 years, he started to eat more ... He eats a lot. (Kaylee)

A mother remarked that her child preferred snacking and ate less at mealtimes:

Not that much ... I mean ... my child eats only ... a little ... More snacking ... This guy ... he's not like any other child who loves to eat ... My child prefers snacking ... Makes people wonder ... how much his snack costs ... from a young age. (Valleri)

\section{Theme 3: Lack of diet diversity}

Mother spoke about a meal of rice in salted water:

It's been a long time ... from 1 year old I guess ... when he started eating independently ... I taught him ... He's very fond of rice mixed with salted water ... Just put salt on freshly cooked rice ... been so long ... Every morning, if we don't have a side dish, we give him that. (Lucy)

Mother spoke about a meal of rice and chicken or rice and eggs:

Sometimes he only eats rice and eggs... vegetables. Only vegetables ... vegetables and an omelet ... Sometimes he eats vegeta- 
bles ... If he's bored with vegetables ... he'll refuse it ... I cook it dry. Sometimes I fry tempe and tofu ... rice with chicken. (Daisy)

Mother described a meal of rice and fish only:

Sometimes he gets tired of it ... He doesn't like vegetables to be constantly served ... We alternate with a dry side dish ... with fish only. (Kimberly)

Mother stated that her child ate rice and vegetable soup:

Rice and vegetables, but he only eats the egg ... and leaves the vegetables... Only if it's soup ... He rather dislikes vegetables ... More into the side dish ... He picks ... what kinds of vegetables... He likes carrots. (Lucy)

Some of mother described her child's eating fruit only once per week:

Once every three days at least ... sometimes once a week ... If I come across a vegetable merchant ... er ... the fruit merchant who wanders in the afternoon ... Only if he comes here ... yes ... But he never eats the whole piece of fruit ... although recently, he eats up to three-quarters of it when I give him one. (Callista)

Mother stated that her child ate only one type of fruit:

He wants to eat only bananas. That's all ... He eats only bananas every day ... but only Lampung bananas ... No Ambonese bananas ... I once served him a bunch of Ambonese bananas that were given by a relative, and he didn't eat it ... Didn't want it. (Kaylee)

Mother said that eggs were the most frequently served side dish:

When we have nothing, we cook eggs for him ... Often that way ... Mostly, we have no side dish ... because my husband is the only one working ... Like this ... That's it ... It's not enough ... It doesn't exist here. (Daisy)

\section{Theme 4: Insufficient iron intake}

Mother indicated that her child was breastfed because he disliked milk formula:

He's only breastfed ... Dislikes milk ... That's why if I go anywhere ... How old is your son? ... I'm sorry. It's not that I don't want to buy ... My child just isn't fond of milk ... He refuses milk formula. (Quinza)

Mother indicated that beans were rarely served or consumed:

He does like beans ... but only occasionally ... Once a week perhaps. (Alice)
Mother stated that her child ate beans in soup only:

Never serve it ... Yet to try it ... . When Posyandu gets green beans ... he only eats the soup. (Kimberly)

Mother stated that she had never provided an iron supplement except for an appetite stimulant:

Never ... However, yesterday I was given Nutrilett from the Community Health Center ... A food supplement. (Daisy)

Another mother stated that she had never given her baby an iron supplement:

Never provide such a thing ... No iron supplement ... When my child 9 months years old in the Cipayung Health Center, he received vitamin $A$ therapy ... The rest, including an iron supplement, was never administered. (Callista)

A participant admitted that her child consumed only meat soup:

Meats [red meat] I am yet to introduce to him ... Only, it's soup ... not the meat ... because the meat has quite a rough texture, right? ... So I serve fish more. (Kimberly)

A mother said that her child disliked meat except for chicken and processed meat, such as sausage and nuggets:

He can't eat that ... Maybe sausage ... processed meat ... He just can't eat meat, and he'll throw up if he eats that ... Only for the processed one perhaps (Ready-toserve)... such as nuggets ... He also likes eggs ... but not meat. (Milly)

\section{Discussion}

A majority of the mothers bought instant baby food and instant steamed rice porridge as a complementary food. Some of their reasons for giving instant baby food to their children were the taste and the lack of time to cook. This confirms the findings of Brown et al., who described the mothers' feeding practices and behaviors regarding children 6-36 months. The compliance with excluding breastfeeding and the recognition of the need for additional foods were relatively high; however, diet diversity and the appropriate feeding frequency were not adhered to well. Packaged and instant foods, e.g., instant soup, and noodles, eggs, milk, oats, and Nestlé baby cereal, were also consumed regularly. ${ }^{14}$ A Study in Philippines also explained that not only low socioeconomic status and vitamin deficiency but also the consumption of instant food contributed to stunting. 15

The results of the present study indicate that the mothers gave solid foods 2-3 times per day to children $>12$ months old; however, the amounts were low and therefore insufficient. This is clearly not in accordance with the WHO recommendations that children aged 9-23 months receive 1-2 different types of supplementary foods 3-4 times each day. ${ }^{16}$ The feeding frequency was not optimal. The feeding frequency was not high for working mothers, mothers with secondary education or higher, or mothers who read magazines or newspapers, listened to the radio, or watched television. The feeding frequency was relatively higher for babies born in healthcare facilities and those whose mothers visited a healthcare facility at least 4 times. ${ }^{17}$ The study also found that mothers who lived in urban areas tended to provide solid foods, half-solid foods, and soft foods at a slightly lower rate than the minimum frequency.

Feeding frequency was related to nutrition status. Some research suggests that lower feeding frequency increases the probability of stunting. Infants who did not receive the minimum dietary diversity and meal frequency were significantly more likely to suffer from stunting. 10 The children of mothers who did not consume enough food during pregnancy and breastfeeding were at 1.6 times higher risk than those of women who consumed enough food during those periods. ${ }^{3}$ A study in Tanzania found that the average amount of food consumed by children with stunted growth was low. ${ }^{18}$ Limited access to food, low availability of food, and lack of nutrition knowledge were contributory factors. ${ }^{19,20}$

Many factors contribute to the lack of dietary diversity. The mothers in the present study did not work outside the home. This is similar to Ng, Dibley, and Agho's study sample. They found that dietary diversity was significantly lower under the following conditions: The mother and father were not employed; one of the parents lacked formal education; the mother was illiterate; the mother was young; the infant was preterm; the infant was delivered at home; the delivery was supervised by midwives; the mother did not read newspapers or magazines, listen to the radio or watch television; and the family was rural and low income. ${ }^{21}$ These findings are similar to those of the present study in which all the participants or mothers had low levels of education. Thus, diet diversity is influenced by many factors, including the mother's education and occupation.

Feeding practices that include the provision of a varied diet can reduce or prevent stunting. A study in India showed that stunted growth was $83 \%$ lower in children whose diet was sufficiently varied. 22 There are relationship between low food diversity, 
as defined by the WHO, and stunting. Food security was an important factor for stunting. The children of families without good food security were 4 times more likely to experience stunting than those of families with better resources. 23

The results of a case study in Vietnam showed that the children of mothers who did not provide dietary diversity were twice as likely to suffer from stunting than children who received an appropriate diet.24,25 This indicates that appropriate feeding practices can have a positive effect on child growth and development. Mothers with adequate media exposure, e.g., daily television and radio consumption, were significantly more likely to ensure the appropriate food diversity and feeding frequency for their children. ${ }^{17}$

The mothers in the study reported the suboptimal consumption of iron-rich foods, e.g., meats, beans, and milk. the mother's education and occupation were significantly associated with iron deficiency. The children of mothers with university or professional experience had a low prevalence of iron deficiency. Children whose diets met the minimum criteria for variety and feeding frequency had a lower prevalence of anemia. ${ }^{15}$ Children who did not get enough daily or weekly multivitamins had a significantly higher prevalence of anemia and iron deficiency.

Some mothers reported that their children did not like meat because of its texture. This confirms the results of study that fewer than $25 \%$ of infants and $62 \%$ of toddlers consumed meat regularly. This indicates that meat consumption can increase with age. Meat consumption can reduce the risk of stunting in children. ${ }^{26}$ The lack of iron has been found to cause stunting. Children who did not consume animal protein had a higher probability of experiencing stunting than those who consumed eggs, meats, and milk. ${ }^{11}$ Roche et al. showed that for infants aged $\geq 6$ months, the consumption of a variety of protein and iron-rich foods is a higher HAZ (Height for Age Z-score) predictor. Iron-rich foods have been known to reduce the risk of stunting. ${ }^{27}$ A study in Tanzania showed that only $6.67 \%$ of the children consumed animal protein. This study concluded that low eating frequency, inadequate nutrient intake, small portion sizes, and limited food variety prevent children from meeting the daily nutritional requirements. ${ }^{18}$

Most of the mothers in this study stated that they rarely gave their children vegetable protein, such as beans. Inadequate amounts of food, such as peas, meat, sardines, and vegetables, can prevent toddlers from meeting the nutritional requirements. ${ }^{18}$ In developing countries, infants who consumed inadequate amounts of animal protein exhibited poor growth. ${ }^{28}$ Iron deficiency can also be a contributory factor.

\section{Conclusions}

The study comprised 15 participants from Jakarta. Four themes were identified to describe the feeding practices for children who experienced stunting. They were the following: i) the provision of instant baby food and instant steamed porridge as complementary foods; ii) a feeding schedule of small portions 2-3 times per day; iii) inadequate dietary variety; and iv) iron deficiency.

\section{References}

1. WHO. Infant and young child feeding: Model chapter for textbooks for medical students and allied health professionals. Geneva: WHO Press; 2009. Available from: https://apps.who.int/iris/bitstream/ handle/10665/44117/9789241597494_e ng.pdf?ua=1

2. Schmidt CW. Beyond malnutrition: The role of sanitation in stunted growth. Environ Health Perspect 2014; 122: 298-303.

3. Tessema M, Belachew T, Ersino G. Feeding patterns and stunting during early childhood in rural communities of Sidama, South Ethiopia. Pan Afr Med J 2013;14:1-12.

4. WHO. WHO global target 2025: Stunting policy brief. 2014. Available from: https://www.who.int/nutrition/ topics/globaltargets_stunting_policybrief.pdf [accessed 16 September 2018].

5. Hoddinott J, Alderman H, Behrman JR, et al. The economic rationale for investing in stunting reduction. Matern Child Nutr 2013;9:69-82.

6. Kar BR, Rao SL, Chandramouli BA. Cognitive development in children with chronic protein energy malnutrition. Behav Brain Funct 2008;4:1-12.

7. Victora CG, Adair L, Fall C, et al. Maternal and child undernutrition: consequences for adult health and human capital. Lancet 2008;371:340-57.

8. Fekadu Y, Mesfin A, Haile D, Stoecker BJ. Factors associated with nutritional status of infants and young children in Somali Region, Ethiopia: A cross-sectional study. BMC Public Health 2015;15:1-9.

9. Zongrone A, Winskell K, Menon P. Infant and young child feeding practices and child undernutrition in Bangladesh: Insights from nationally representative data. Public Health Nutr 2012;15:1697704.
10. Udoh EE, Amodu OK. Complementary feeding practices among mothers and nutritional status of infants in Akpabuyo Area, Cross River State Nigeria. SpringerPlus. 2016;5:1-19.

11. Krasevec J, An X, Kumapley R, et al. Diet quality and risk of stunting among infants and young children in low and middle-income countries. Matern Child Nutr 2017;13:1-11.

12. Rakotomanana H, Gates GE, Hildebrand D, Stoecker BJ. Situation and determinants of the infant and young child feeding (IYCF) indicators in Madagascar: analysis of the 2009 demographic and health survey. BMC Public Health 2017;17:1-9.

13. Menon P, Bamezai A, Subandoro A, et al. Age-appropriate infant and young child feeding practices are associated with child nutrition in India: insights from nationally representative data. Matern Child Nutr 2015;11:73-87.

14. Brown K, Henretty N, Chary A, et al. Mixed-methods study identifies key strategies for improving infant and young child feeding practices in a highly stunted rural indigenous population in Guatemala. Matern Child Nutr 2016;12:262-77.

15. Rohner F, Bradley AW, Grant JA, et al. Infant and young child feeding practices in urban Philippines and their associations with stunting, anemia, and deficiencies of iron and vitamin A. Food Nutr Bull 2013;34:17-34.

16. World Health Organization (WHO) Indicators for Assessing Infant and Young Child Feeding Practices Part II: Measurement. Geneva: WHO Press; 2010. Available from: https://apps.who. int/iris/bitstream/handle/10665/44306/9 789241599290_eng.pdf?sequence $=1$.

17. Joshi N, Agho KE, Dibley MJ, et al. Determinants of inappropriate complementary feeding practices in young children in Nepal: Secondary data analysis of demographic and health survey 2006. Matern Child Nutr 2012;8: 45-59.

18. Kulwa KBM, Mamiro PS, Kimanya $\mathrm{ME}$, et al. Feeding practices and nutrient content of complementary meals in rural central Tanzania: Implications for dietary adequacy and nutritional status. BMC Pediatr 2015;15:1-11.

19. Saha KK, Frongillo EA, Alam DS, et al. Household food security is associated with growth of infants and young children in rural Bangladesh. Public Health Nutr 2009;12:1556-62.

20. Campbell KJ, Abbott G, Spence AC, et al. Home food availability mediates associations between mothers' nutrition 
knowledge and child diet. Appetite 2013;71:1-6.

21. Ng CS, Dibley MJ, Agho KE. Complementary feeding indicators and determinants of poor feeding practices in Indonesia: A secondary analysis of 2007 demographic and health survey data. Public health nutr 2012;15:827-39.

22. Ahmad I, Khalique N, Khalil S, et al. Dietary diversity and stunting among infants and young children: A cross sectional study in Aligarh. Indian J community Med 2018;43:34-6.

23. Paudel R, Pradhan B, Wagle RR, et al. Risk factors for stunting among chil- dren: A community based case control study in Nepal. Kathmandu Univ Med J 2012;39:18-24.

24. Reyes H, Pérez-Cuevas R, Sandoval A, et al. The family as a determinant of stunting in children living in conditions of extreme poverty: A case control study. BMC Public Health 2004; 4:1-10.

25. Anh, VTN, Chompikul J, Isaranurug S. Relationship between stunting and food provided to children aged from 6 to 24 months in Soc Son District, Hanoi. J Public Health and Dev 2009;7:43-58.

26. Krebs NF, Mazariegos M, Tshefu A, et al. Meat consumption is associated with less stunting among toddlers in four diverse low-income settings. Food Nutr Bull 2011;32:185-91.

27. Roche ML, Gyorkos TW, Blouin B, et al. Infant and young child feeding practices and stunting in two highland provinces in Ecuador. Matern Child Nutr 2017;13:1-15.

28. Leonard WR, Dewalt KM, Stansbury JP, McCaston MK. Influence of dietary quality on the growth of highland and coastal Ecuadorian children. Am J Hum Biol 2000;12:825-37. 